\title{
09 COMMUNITY BASED STUDY ON PARENT RELATED CONTRIBUTORY FACTORS FOR UNINTENTIONAL INJURIES AMONG PRESCHOOL CHILDREN IN SRI LANKA
}

doi:10.1136/injuryprev-2012-040590d.9

${ }^{1} \mathrm{DC}$ Samarakkody, ${ }^{2} \mathrm{DN}$ Fernando, ${ }^{3} \mathrm{RJ}$ McClure. ${ }^{1}$ Injury Prevention Division, Ministry of Health, Sri Lanka; ${ }^{2}$ University of Colombo, Sri Lanka; ${ }^{3}$ Monash University Accident Research Centre, Australia

Background Unintentional injuries are one of the leading causes of hospitalisation among preschool children in Sri Lanka resulting disability and death. Though majority of unintentional injuries among this age group occur when the children are at home with their parents, there is dearth of information on parent related contributory factors.

Objectives To ascertain parent related contributory factors for unintentional injuries among preschool children.

Methods A community based sample of 1117 preschool children was recruited using a two tier randomisation process. Parents of participating children completed an interviewer administered questionnaire that recorded the parent's recollection of their child having an unintentional injury needed medical attention, within 6 months prior to the interview. In addition parents completed measures assessing type and quality of parenting, quality of marital life, exposure to family stressors and Beck Depression Inventory. Psychosocial stimulation potential of child's home environment was assessed by the Home Observation for Measurement of the Environment inventory.

Results Logistic regression analysis demonstrated poor quality of parenting (OR 4.9, CI 2.4 to 9.9) and depressive mental health status (OR 4.5, CI 2.5 to 7.9) of the mother, poor quality of parent's marital life (3.08, CI 1.8 to 5.2$)$ and inadequacy of psychosocial stimulation at home (OR 2.4, CI 1.2 to 4.8) as the variables that predict the occurrence of unintentional injuries among the study group.

Contribution to the Field Identification of parent related risk factors for unintentional injuries among preschool children will enable policy makers to plan and implement injury prevention programmes addressing these factors. 